\title{
Analisa Mengenai Pembatalan Merek Cap Kaki Tiga
}

Disusun oleh :

Fadiah Azzahra Gusti - 191000034

Hanifa Nurfitriani - 191000022

Maya Herma sa'ari - 191000036

Muhamad Faizal H 191000002

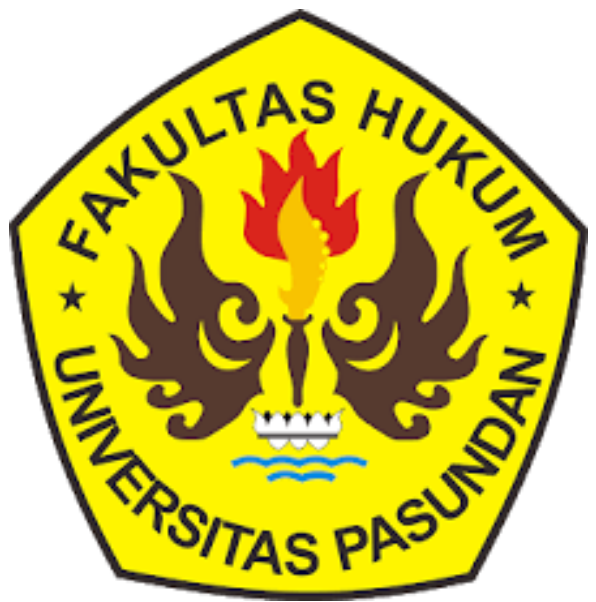

FAKULTAS HUKUM

UNIVERSITAS PASUNDAN BANDUNG

TAHUN AJARAN 2020/2021 


\begin{abstract}
ABSTRAK
Pembatalan merek dapat Terjadi kapan saja selama merk tersebut masih beredar dan masih terdaftar. Hal ini dapat terjadi dikarenakan adanya itikad tidak baik yang dilakukan oleh pendaftar merek. Misalnya terdapat kesamaan pada pokoknya dan atau keseluruhan pada merek atau logo. Peristiwa ini dapat kita lihat dengan bentuk nyata dalam kasus Pembatalan Merek Cap Kaki Tiga. Pembatalan Merek tersebut terjadi karena adanya kemiripan logo pada kemasan Cap Kaki Tiga dengan lambang/ logo negara Isle of Man. Terhadap pembatalan tersebut, akhirnya terjadi penarikan Sertifikat Merek Cap Kaki Tiga milik Wen Ken Drug. Walaupun Pembatalan Merek sudah diputuskan, Cap Kaki Tiga masih beredar di pasaran. Hal ini dikarenakan tidak ada putusan yang mengumumkan Cap kaki Tiga untuk berhenti beredar di pasaran. Dan untuk upaya hukum demi hilangnya kerugian terhadap Isle Of Man, pemohon dapat mengajukan Penetapan Sementara selama persidangan masih berlanjut.
\end{abstract}

Kata Kunci : Pembatalan Merek, Penetapan Sementara, Merek

\begin{abstract}
Trademark cancellation can occur at any time as long as the brand is still in circulation and is still registered. This can happen due to bad faith committed by the registrant of the mark. For example, there are similarities in essence and / or the whole of the brand or logo. We can see this incident in real form in the case of Cap Kaki Tiga Mark Cancellation. The cancellation of the Mark occurred because of the similarity of the logo on the Cap Kaki Tiga packaging to the coat of arms / logos of the Isle of Man state. Regarding the cancellation, Wen Ken Drug finally withdrew the Trademark Mark Certificate. Even though the Brand Cancellation has been decided, Cap Kaki Tiga is still circulating in the market. This is because there is no decision that announces Cap Kaki Tiga to stop circulating in the market. And for legal remedies for loss of damages to the Isle Of Man, the applicant can file a Provisional Determination as long as the trial continues.
\end{abstract}

Keywords: Mark Cancellation, Provisional Determination, Brand 


\section{LATAR BELAKANG PENELITIAN}

Perkembangan globalisasi dan teknologi informasi memberikan perubahan besar terhadap pasar perekonomian global. Banyak inovasi-inovasi baru yang muncul ke muka bumi terlebih lagi inovasi dalam dunia perdagangan, banyak perusahaan yang berlomba-lomba untuk berinovasi dan mengembangkan produk-produk yang mereka produksi. Contohnya di era ekonomi berbasis kreativitas ini, terjadi pergeseran model ekonomi dari model owning economy ke arah sharing economy yang dipandang lebih efektif dalam pemanfaatan sumber daya ekonomi dengan keuntungan yang mendukung upaya pemerataan ekonomi dan kesejahteraan sosial ${ }^{1}$. Selain itu, pengusahapengusaha yang baru memulai usahanya juga termotivasi dan terinspirasi untuk berinovasi. Tetapi, seiring dengan berkembangnya jaman dan semakin banyak produk yang dihasilkan mengakibatkan adanya kesamaan atau kemiripan antar produk-produk tersebut. Maka dari itu, untuk melindungi produk tersebut para pengusaha atau badan hukum lainnya harus menandai produk dengan Merek. Dalam Pasal 1 angka 1 UndangUndang Nomor 15 Tahun 2001 Tentang Merek menyatakan bahwa, "Merek adalah tanda yang berupa gambar, nama, kata, huruf-huruf, angka-angka, susunan warna, atau kombinasi dari unsur-unsur tersebut yang memiliki daya pembeda dan digunakan dalam kegiatan perdagangan barang atau jasa"2. Merek berfungsi sebagai identitas produk. Namun, Merek ini harus didaftarkan agar memiliki kevalidasian dan menimbulkan perlindungan hukum terhadap Merek tersebut.

Pendaftaran merek merupakan suatu hal yang penting dalam kegiatan komersial. Pendaftaran ini berfungsi sebagai alat bukti bagi pemilik yang berhak atas merek yang di daftarkan. Tetapi tidak semua merek bisa didaftarkan, ada beberapa hal yang dapat mengakibatkan penolakan terhadap pendaftaran merek contohnya merek yang memiliki kesamaan secara keseluruhan atau hanya pada pokoknya yang dimohonkan pendaftar oleh orang lain untuk barang/jasa sejenisnya. Bagi produk yang telah terdaftar juga dapat dilakukan Pembatalan Merek jika suatu hari Merek tersebut melanggar ketentuan Undang-Undang Merek.

Peristiwa Pembatalan Merek ini dialami oleh PT Kino Indonesia Tbk. terhadap salah satu produksinya yaitu larutan penyegar Cap Kaki Tiga. Hal ini dikarenakan logo yang digunakan oleh Cap Kaki Tiga menyerupai Lambang Isle of Man yang digunakan pada

\footnotetext{
${ }^{1}$ Tisni Santika, View of PENGEMBANGAN PRODUK INDIKASI GEOGRAFIS DALAM KONTEKS SHARING ECONOMY DI ERA DISRUPSI DIGITAL (unpas.ac.id)

2 Dagang PT Wen Ken Drug Co.Pte.Ltd Berdasarkan Undang-Undang No 15 Tahun 2001 Tentang Merek hal. 3
}

http://repository.maranatha.edu/23035/3/1387023 Chapter1.pdf 
atribut dan atau mata uang. Walaupun Merek Cap Kaki Tiga telah dibatalkan, Direktur Utama Kino tetap menjual dan mendistribusikan Merek Cap Kaki Tiga.

Berdasarkan latar belakang penelitian tersebut maka penulis tertarik untuk membahas lebih lanjut atas "Penelitian Mengenai Pembatalan Merek Cap Kaki Tiga yang Masih Beredar di Pasaran”.

\section{IDENTIFIKASI MASALAH}

Permasalahan penelitian yang penulis ajukan ini dapat diidentifikasi permasalahannya sebagai berikut :

1. Mengapa Merek Cap Kaki Tiga dibatalkan dan masih dapat beredar di pasaran?

2. Bagaimana hasil Pertimbangan Hukum Hakim dalam putusan Mahkamah Agung Nomor 582 K/PDT.Sus-HAKI/2013 tentang pembatalan merek Cap Kaki Tiga dan terhadap putusan tersebut apakah Merek Cap Kaki tiga masih dapat beredar?

3. Bagaimana upaya hukum yang dapat dilkakukan untuk melindungi Hak Isle of Man jika merek yang melakukan pelanggaran tetap beredar di pasaran?

TINJAUAN PUSTAKA
Merek larutan Cap Kaki Tiga pertama kali di dirikan pada tahun 1937 oleh Wen Ken Drug co (Pte) Ltd. Minuman Larutan Cap Kaki Tiga ini baru Masuk ke Indonesia pada tahun 1978 dan dikelola oleh PT Sinde Budi Sentosa dengan Hak Pendistribusian diberikan kepada PT duta Lestari. Pada kemasan Cap Kaki Tiga terdapat logo merek berupa 3 Kaki yang masing - masingnya memiliki arti tersendiri, yaitu :

- Kaki yang terarah ke atas melambangkan kehidupan yang harus selalu terarah pada ajaran tentang kebenaran yang bersumber dari yang maha kuasa.

- Kaki yang berpijak ketanah melambangkan kerja keras yang harus dilakukan untuk mencapai sebuah kesuksesan.

- Kaki yang bersimpuh melambangkan kerendahan hati yang harus dimiliki setiap orang yang berakhlak mulia. ${ }^{3}$

Logo Merek inilah yang kemudian menimbulkan permasalahan Hak Kekayaan Intelektual, dimana Logo tersebut digugat Oleh Warga negara Inggris Russel Vince karena dianggap menyerupai dengan Lambang Negara isle of man

\section{Pembatalan Merek Cap Kaki Tiga dan Izin Pemasaran}

\footnotetext{
${ }^{3}$ Lentera kecil. Larutan Cap Kaki Tiga https://lenterakecil.com/larutan-cap-kaki-tiga/
} 
Sesuai dengan Putusan Mahkamah Agung Nomor 582 K/PDT.SusHAKI/2013 menyatakan bahwasanya Merek Cap Kaki Tiga yang telah terdaftar sebelumnya menjadi batal demi hukum ataupun batal dengan sendirinya disebabkan pihak tergugat yakni merek Cap Kaki Tiga memiliki itikad tidak baik dengan meniru lambang/simbol/emblem Isle of $\mathrm{Man}^{4}$. Isle of Man bukan merupakan bagian dari Inggris namun hanya bagian dari dependensi Mahkota Great Britania Raya, yang terletak di Laut Irlandia dan tidak berstatus sebagai anggota Uni Eropa tapi merupakan bagian dari kawasan serta bea cukai Uni Eropa. Isle of Man mempunyai pemerintahannya sendiri namun berada dibawah hukum Inggris dan untuk urusan luar negeri serta pertahanannya diwakili oleh negara Inggris. ${ }^{5}$

Pembatalan merek Cap Kaki Tiga telah diputus sejak tanggal 2 September 2016. Walaupun begitu pemegang lisensi merek Cap Kaki Tiga di Indonesia Tbk. memutuskan untuk tetap beredar dengan nama merek dan logo yang sama. Karena menurut Direktur Perusahaan Cap Kaki Tiga dalam Putusan MA tentang Pembatalan
Merek Cap Kaki Tiga ini, pada pokoknya hanya membatalkan seluruh sertifikat Merek Cap Kaki Tiga milik perusahaan Wan Ken Drug.Co.Ltd. di Indonesia. Maka, mereka tetap mengedarkan Kemasan dengan Merek dan logo tersebut sehubungan Putusan MA tidak menyebutkan larangan untuk menggunakan logo Cap Kaki Tiga yang mirip dengan lambang Isle of Man dan larangan untuk beredarnya produk tersebut.

\section{Hasil Pertimbangan Hakim Dalam} Putusan Mahkamah Agung Nomor 582 K/PDT.Sus-HAKI/2013 Tentang Pembatalan Merek Cap Kaki Tiga dan Akibat Hukumnya

Putusan ini merupakan putusan kasasi, dimana Wen Ken drug dan Kementrian Hukum dan HAM Republik Indonesia cq Direktorat Jenderal Hak Kekayaan Intelektual cq Direktorat Merek menjadi Para Pemohon Kasasi dahulu tergugat dan turut tergugat. Sedangkan Russel Vince menjadi Termohon Kasasi dahulu Penggugat. Kasasi ini terjadi karena pihak Tergugat dan Tururt Tergugat tidak puas dengan hasil Putusan Pengadilan Nomor 66/Merek/2012/PN.Niaga JKT.Pst., tanggal 11 Juni 2013 dimana putusan
${ }^{4}$ Putusaan Mahkamah Agung Nomor 582 K/PDT.SusHAKI/2013 hal. 125
${ }^{5}$ SS Arifah hal. 5 http://digilib.uinsgd.ac.id/2807/4/4_bab1.pdf 
tersebut menyatakan hal-hal sebagai

berikut :

- Menolak tuntutan Provisi Penggugat

- Mengabulkan gugatan penggugat untuk Sebagian

- Menyatakan tergugat telah melakukan itikad tidak baik dalam mendaftarkan seluruh Merek Dagang "Cap Kaki Tiga”

- Menyatakan bahwa seluruh Merek Dagang Cap Kaki Tiga merupakan tiruan dari Lambang/Logo Mata uang Isle of Man

- Membatalkan atau setidak-tidaknya menyatakan batal seluruh Sertifikat Merek Cap Kaki Tiga atas nama Tergugat dan mencoretnya dari Daftar Umum Merek.

- Memenrintahkan Turut Tergugat untuk tunduk dan taat pada Putusan Pengadilan Niaga dalam hal ini adalah dengan mencoret pendaftaran merek Cap Kaki Tiga

Namun, terhadap putusan tersebut Tergugat dan Turut Tergugat tidak puas dan Keberatan dengan Putusan Hakim dan ingin mengajukan kasasi dengan alasan - alasan berikut :

- Bahwa Russel Vince tidak memiliki kapasitas untuk bertindak sebagai penggugat dalam perkara ini, dikarenakan ia hanya seorang warga negara inggris dan bukanlah subjek hukum yang ditunjuk untuk mewakili negara Isle of Man. ${ }^{6}$

- Bahwa Russel Vince juga tidak memiliki alas/kepentingan hukum untuk bertindak selaku Penggugat dalam perkara ini ${ }^{7}$

- Bahwa gugatan Russel Vince harus dinyatakan tidak dapat diterima karena hal ini menjadi kompetensi Pengadilan di Singapura ${ }^{8}$

- Bahwa gugatan Russel Vince Kabur dan tidak jelas dikarenakan tidak ada sinkronisasi antara kepentingan penggugat dengan permintaan provisi

Dalam Putusan Mahkamah Agung Nomor 582 K/PDT.Sus-HAKI/2013 yaitu berdasarkan Putusan Kasasi ini, dapat ditarik kesimpulan dari Pertimbangan Hukum hakim sebagai berikut :

1) Permohonan Kasasi dari Tergugat dan Tururt tergugat tidak dapat dibenarkan, oleh karena Judec Facti tidak salah menerapkan hukum.

2) Bahwa Pasal 6 ayat (3) huruf b yang menyebutkan ;

"Permohonan juga harus ditolak oleh Direktorat Jenderal apabila Merek tersebut:

\footnotetext{
${ }^{6}$ Putusaan Mahkamah Agung Nomor 582 K/PDT.Sus-HAKI/2013 hal. 29
} 
a. ...dan seterusnya

b. Merupakan tiruan atau menyerupai nama atau singkatan nama atau singkatan nama, bendera, lambang atau simbol atau emblem Negara atau lembaga nasional maupun internasional, kecuali atas persetujuan tertulis dari pihak yang berwenang

Dalam perkara ini Direktorat Merek telah mengabaikan ketentuan Pasal 6 ayat (3) sub b Undang Undang Nomor 15 Tahun 2001 tentang Merek tersebut, tegasnya dengan demikian maka "pendaftaran tersebut batal dengan sendirinya/batal demi hukum" karena sudah dilarang oleh hukum akan tetapi Direktorat tetap mendaftarnya/melakukannya

3) Bahwa sekalipun tidak ada pihak yang mengajukan keberatan terhadap lambang/simbol sesuatu Negara i.c Negara Isle of Man, disebabkan secara faktuil nampak jelas cap kaki tiga adalah lambang Negara Isle of Man, maka Direktorat Merek harus menolak dan tidak mendaftarkan merek Cap Kaki Tiga

4) Bahwa karena pendaftaran itu dilarang, maka merek yang sudah didaftar menjadi batal demi hukum ataupun batal dengan sendirinya.

Sehubungan dengan putusan tersebut maka Merek Cap Kaki Tiga ditarik dan dicoret dari Daftar Umum Merek Direktorat Jendral Hak Kekayaan Intelektual dengan segala akibat hukumnya.

Akibat hukum yang terjadi apabila terdapat pembatalan merek adalah :

- Berakhirnya perlindungan hukum terhadap merek

- Berakhirnya semua perjanjian yang berkaitan dengan Merek tersebut. Contohnya perjanjian lisensi

- Berakhirnya kepemilikan terhadap merek tersebut.

\section{Upaya Hukum Yang Dapat} Dilakukan Untuk Melindungi Hak

\section{Isle of Man}

Indonesia merupakan negara yang menganut sistem perlindungan merek dengan prinsip First to File, dimana pendaftar pertamalah yang berhak mendapatkan perlindungan terhadap merek yang di daftarkan. Namun prinsip ini tidak bersifat mutlak, karena kemungkinan akan terjadi Pembatalan Merek jika terdapat Sengketa di dalamnya. Pembatalan merek akan mengakibatkan pihak yang tergugat 
dihilangkan eksistensi pendaftaran mereknya dari Daftar Umum Merek (DUM) atau dibatalkan keabsahan hak berdasarkan sertifikat merek.

Selama proses persidangan berjalan agar tidak mengakibatkan kerugian, kuasa hukum pemohon dapat mengajukan Penetapan Sementara (interlocutory injunction dalam bentuk temporary restraining order) yang diatur dalam Peraturan Mahkamah Agung (PERMA) Nomor 5 Tahun 2012. Tetapi dalam penulisan ini, dikhususkan hanya terhadap sengketa/kasus Merek. Penetapan ini hanya diberikan oleh pengadilan apabila pihak pemohon dapat membuktikan dengan kuat bahwasanya terdapat pelanggaran Hak Kekayaan Intelektual yang mengakibatkan kerugian baik aktual maupun potensi yang diderita.

Permohonan penetapan sementara dapat dilakukan secara tertulis oleh pihak Pemohon dan ditujukan kepada Ketua Pengadilan dengan persyaratan yaitu melampirkan bukti bukti bahwasanya memang telah terjadi sengketa merek dan bukti kepemilikan merek yang kuat. Setelah permohonan diterima pihak Pengadilan akan memberitahukan kepada pihak Termohon dan memberikan kesempatan pada pihak termohon untuk memberikan keterangannya. Hakim Pengadilan yang memeriksa sengketa tersebut harus memutuskan untuk mengubah, membatalkan, atau menguatkan penetapan sementara paling lama 30 hari sejak dikeluarkannya penetapan sementara tersebut.

\section{HASIL ANALISIS}

Berdasarkan penelitian yang telah dilakukan oleh penulis maka hasil analisis yang didapat adalah sebagai berikut :

1. Minuman Larutan Cap Kaki Tiga merupakan produk milik Wen Ken Drug Co.Ltd dimana merek ini dibatalkan akibat logo pada kemasan minumannya merupakan tiruan dari logo/mata uang Negara Isle Of Man. Berdasarkan Putusan Mahkamah Agung Nomor 582 K/PDT.Sus-HAKI/2013 telah memutuskan pembatalan merek Cap Kaki Tiga. Produk minuman ini masih beredar di pasaran walaupun mereknya sudah dibatalkan oleh putusan Mahkamah Agung. Berdasarkan hasil penelitian para penulis, peredaran produk yang mereknya telah dicabut atau dibatalkan tidak mempunyai masalah apabila ia masih beredar di pasaran dengan logo dan merek yang sama 
apabila tidak tercantum dalam putusan bahwasanya merek tersebut harus berhenti beredar. Namun dalam kasus ini, Russel Vince memohon Pengadilan untuk menarik atau melarang pemakaian logo yang menyerupai logo Isle of Man, berdasarkan permintaan itu Mahkamah Agung tidak nengabulkan permohonan tersebut. Namun, pengadilan meminta Cap Kaki Tiga untuk mengubah logo nya dan akhirnya Cap Kaki Tiga Beritikad baik untuk mengganti logo pada kemasan minumannya.

2. Putusan Mahkamah Agung Nomor 582 K/PDT.Sus-HAKI/2013 ini menyatakan tentang Pembatalan Merek Cap Kaki tiga yang disebabkan oleh peniruan logo/lambang mata uang Isle of Man. Pembatalan merek ini memiliki akibat hukum yang cukup serius yaitu berakhirnya seluruh perlindungan hukum dan perjanjian yang berkaitan dengan Merek tersebut. Namun tidak ada akibat hukum atau aturan hukum yang melarang untuk Merek tersebut tetap beredar di pasaran. Maka dari hasil analisis yang dilakukan oleh penulis, Merek Cap Kaki Tiga masih dapat beredar di Pasaran dan tetap terus mendistribusikan produknya. Walaupun Penggugat sempat menggugat untuk memberhentikan produksi dan menarik seluruh produk Cap Kaki Tiga, gugatan tersebut ditolak oleh Pengadilan karena dianggap terlalu berlebihan dan melanggar ketentuan undang-undang. Jadi, pada kesimpulannya produk Cap Kaki Tiga masih tetap diperbolehkan untuk beredar di pasaran,

3. Penetapan sementara merupakan upaya hukum yang dapat dilakukan oleh pemegang merek untuk melindungi hak nya. Namun, penetapan sementara ini hanya bisa diajukan oleh pihak yang terkait yaitu pemegang merek. Maka, berdasarkan hasil penilitian penulis demi melindungi hak pemegang logo terhadap pelanggaran merek yang dilakukan oleh Wen Ken Drug, kuasa hukum Russel Vince dapat memohonkan penetapan sementara.. Hal ini berfungsi untuk memberikan waktu terhadap pihak yang menanggung kerugian untuk mengkalkulasikan jumlah kerugian yang dideritanya.

\section{KESIMPULAN}

Dalam hal merek ataupun logo jika ingin mempunyai kekuatan hukum maka penting untuk mengajukan pendaftaran merek ataupun logo. Sebuah produk penting sekali untuk memberikan merek ataupun logo kepada produk agar menjadi pembeda dari produk-produk lain yang akan di produksi, 
akan tetapi pastikan merek ataupun logo yang akan di pakai belum digunakan baik oleh orang, perusahaan, ataupun negara.

Maka berdasarkan pembahasan dan hasil penelitian dapat diambil kesimpulan bahwasanya Pembatalan Merek minuman Larutan Cap Kaki Tiga ini diakibatkan oleh adanya kesamaan atau peniruan logo terhadap logo/mata uang Isle of Man yang ditetapkan oleh Putusan Mahkamah Agung Nomor $582 \quad$ K/PDT.Sus-HAKI/2013. Terhadap hasil putusan tersebut, Russel Vince memohonkan untuk produk minuman Larutan Cap Kaki Tiga tidak boleh beredar di pasaran atau harus mengganti logonya.

Namun, merek Cap Kaki Tiga masih memiliki hak untuk beredar di pasaran. Hal ini disebabkan gugatan yang diajukan oleh penggugat untuk memberhentikan produksi dan penarikan seluruh produk Cap Kaki Tiga di tolak oleh Pengadilan karena dianggap terlalu berlebihan dan tidak sesuai dengan Undang-undang.

\section{DAFTAR PUSTAKA}

\section{A. Jurnal}

Jurnal Universitas Kriaten Maranatha. "Analisa Terhadap Putusan Nomor 66/Merek/2012/PN.Niaga.JKT.PST

Tentang Merek Dagang PT Wen Ken

Drug Co.Pte.Ltd Berdasarkan UndangUndang No 15 Tahun 2001 Tentang
Merek

http://repository.maranatha.edu/23035/3/ 1387023_Chapter1.pdf diakses pada tanggal 12 Maret pukul 20.21 WIB

Onibala, Mikry. 2017. Penetapan Sementara Pengadilan Niaga Sebagai Bentuk Upaya Hukum Perlindungan Hak Pemegang Merek, ejournal Fakultas Hukum Universitas Sam Ratulangi https://ejournal.unsrat.ac.id/index.php/a dministratum/article/download/18019/1 $\underline{7543}$ diakses pada tanggal 15 Maret 20.20 WIB

Pratama, Putu Hendra. 2014. Perlindungan Hukum Pemilik Merek Terdaftar Dan Relevansinya Terhadap Pratek Persaingan Usaha Tidak Sehat, Vol.02, No.02, Jurnal Kertha Semaya Fakultas Hukum Universitas Udayana, h.5 URL https://ojs.unud.ac.id/index.php/kerthas emaya/article/view/8197 diakses pada 15 Maret 2021 pukul 18.37 WIB

Safitri, Putri Ari dan Ni Luh Gede Astariyani. Pembatalan Merek Oleh Pihak Yang Tidak Berhak : Kajian Itikad Baik https://ojs.unud.ac.id/index.php/kerthaw icara/article/download/57751/33715 diakses pada tanggal 12 Maret 2021 pukul 17.47 WIB

Santika, Tisni. Pengembangan Produk Indikasi Geografis Dalam Konteks Sharing Economy di Era Disrupsi Digital View of PENGEMBANGAN 
$\underline{\text { PRODUK INDIKASI GEOGRAFIS }}$

DALAM KONTEKS SHARING

ECONOMY DI ERA DISRUPSI

DIGITAL (unpas.ac.id) diakses pada tanggal 16 Maret 2021 pukul 22.19 WIB

Sudjana. Akibat Hukum Pengahpusan dan Pembatalan Merek Terdaftar terhadap Hak

Merekhttps://ojs.unikom.ac.id/index.ph p/law/article/view/3076\#: :text=Akibat \%20hukum\%20Penghapusan $\% 20$ merek \%20terdaftar,merasa\%20dirugikan\%3B \%20(2). Diakses pada tanggal 17 Maret 2021 pukul $12.50 \mathrm{WIB}$

Tambunan, Albert Renaldi. Perlindungan Hukum Pemegang Merek Akibat Pembatalan Merek Oleh Direktorat Merek dan Indikasi Geografis http://lib.unnes.ac.id/41823/1/81114160 91.pdf diakses pada tanggal 13 Maret $202111.20 \mathrm{WIB}$

\section{B. Ketentuan Perundang-Undangan}

Undang Undang Nomor 15 Tahun 2001 tentang Merek

Peraturan Mahkamah Agung Nomor 5 Tahun 2012 Tentang Penetapan Sementara

\section{Sumber Lain}

Halimah Nur Pratiwi, Enam Alasan Pentingnya Pendaftaran Merek, https://smartlegal.id/smarticle/2019/02/2 0/enam-alasan-pentingnya-pendaftaranmerek/ diakses pada tanggal 13 Maret 2021 pukul 12.13 WIB.

Kenny Wiston, SH, LL.M, Penetapan Sementara Pengadilan Niaga Untuk Pelanggaran HKI https://m.hukumonline.com/berita/baca/ hol13441/penetapan-sementarapengadilan-niaga-untuk-pelanggaranhki/ diakses pada tanggal 12 Maret 2021 pukul 15.40 WIB

Rizal, Merek Cap Kaki Tiga Resmi Dicoret Pemerintah, Ini Kesalahan Fatal Mereka, $\quad$ https://www-idntimescom.cdn.ampproject.org/v/s/www.idnti mes.com/news/indonesia/amp/rizal/mer k-cap-kaki-tiga-resmi-dicoretpemerintah-ini-kesalahan-fatalmereka?amp_js_v=a6\&amp_gsa $=1 \& u s$ $q p=m q 331 \mathrm{AQHKAFQArABIA} \% 3 \mathrm{D} \% 3$ D\#aoh $=16155604637851 \& \mathrm{csi}=1 \&$ refer rer=https $\% 3 \mathrm{~A} \% 2 \mathrm{~F} \% 2 \mathrm{Fwww}$. google.co m\&amp tf=Dari\%20\%251\%24s\&amps hare $=$ https $\% 3 \mathrm{~A} \% 2 \mathrm{~F} \% 2 \mathrm{Fwww} . i d n t i m e s$ .com\%2Fnews \%2Findonesia\%2Frizal $\% 2$ Fmerk-cap-kaki-tiga-resmi-dicoretpemerintah-ini-kesalahan-fatal-mereka diakses pada tanggal 13 Maret 2021 pukul 14.14 WIB

Sumatera Ekspres online, Cap Kaki Tiga Ditarik.

https://bpkn.go.id/uploads/document/ab 
18877ae73dd42905ed456aa34280ede9e

856b0.pdf diakses pada tanggal 13

Maret 2021 pukul 13.58 WIB 